\title{
Computational Modelling of Three-phase Stent-based Delivery
}

\author{
Akash Pradip Mandal and Prashanta Kumar Mandal* \\ Department of Mathematics, Visva-Bharati University, Santiniketan-731235, West Bengal, India
}

\begin{abstract}
Background and Objective: Treatment of arterial lesions using drug-eluting stent is now a gold standard method, however, the mechanisms of drug uptake and its retention is not well understood. In most of the computational studies, only the binding of drug to specific receptor is considered; but it is well established that when the drug binds to the specific receptor, there is also occurrence of non-specific binding caused by the trapping of drug in the extracellular matrix. When non-specific binding is not subtracted from total binding to give receptor-mediated binding, a description of receptor/ligand requires that effects of non-specific binding be considered.
\end{abstract}

Methods: We construct a computational model of the drug transport within the arterial wall. The governing equations, along with the suitable boundary conditions, are solved numerically in an explicit manner. Necessary stability criteria have been checked in our in-house FORTRAN code.

Results: The simulated results in this study predict that the penetration length of both free and non-specific bound drug increases with increase in time, and ultimately saturation of binding sites takes place; however, specific bound drug becomes totally absorbed at the adventitial boundary. The concentration of free drug is always higher in the case of the single bound phase model than that of the double bound phase model.

Conclusion: Because local concentration of free drug is inextricably linked to the binding and saturation of binding, our results provide a potential explanation for the success of stent-based delivery.

\section{Introduction}

The drug-eluting stent (DES) is now a common treatment for atherosclerosis. Placed into the narrowed artery, it serves to reopen the artery and slowly release drug to inhibit cell proliferation. The DES consists of three parts, namely the stent platform, a polymer coating that binds the drug to the stent and releases drug, and the drug. Success of the DES is usually associated with the effective delivery of potent therapeutics to the target site, at a sufficient concentration for a sufficient time and in a biologically active state. Although DESs are now the primary choice for treatment of ath-

Keywords: Embedded drug-eluting stent; Free drug; Specific binding; Non-specific binding; Nonlinear saturable reversible chemical reaction.

Abbreviations: DES, drug-eluting stent; SR, specific receptor; ECM, extra cellular matrix; NDC, normalised drug concentration; $\mathrm{NDC}_{\mathrm{FREE}}$, normalised free drug concentration; $\mathrm{NDC}_{\mathrm{SR}}$, normalised bound drug concentration in $\mathrm{SR}$ phase; $\mathrm{NDC}_{\mathrm{ECM}}$, normalised bound drug concentration in ECM phase.

Received: January 14, 2017; Revised: March 21, 2017; Accepted: March 30, 2017

*Correspondence to: Prashanta Kumar Mandal, Department of Mathematics, VisvaBharati University, Santiniketan-731235, West Bengal, India. Tele/Fax: +91-3463261029, E-mail: pkmind02@yahoo.co.uk

How to cite this article: Mandal AP, Mandal PK. Computational Modelling of Threephase Stent-based Delivery. J Explor Res Pharmacol 2017;2(2):31-40. doi: 10.14218/ JERP.2017.00001. erosclerosis, questions still arise in regard to longevity and safety. ${ }^{1}$

To investigate the drug release mechanism, various models have been developed, including the one-dimensional model, ${ }^{2-4}$ the twodimensional or axi-symmetric model and the three-dimensional model. ${ }^{5-13}$ The drug release process is also affected by some physical properties, namely the geometrical design of the stent itself, the mechanical properties of the stent's material and the chemical properties of the drug. ${ }^{14,15} \mathrm{~A}$ number of experimental and numerical studies on DES have been published in recent years to address such issues as longevity and safety. ${ }^{3,11,16-22}$

Since binding of the ligand to the cell surface receptors has been amenable to direct experimental investigation for roughly the past three decades, ${ }^{23,24}$ a sincere attempt has also been made to take into account the binding event that occurs on the cell surface. However, no such attempt has been made to consider the aspects of trafficking process, cell signaling or receptor mobility. The first mathematical model developed to investigate binding kinetics used a constant partition coefficient. ${ }^{25}$ But, it was too simple to predict the distribution of drug or to consider retention of the drug in the arterial wall. Some authors used a chemical reaction to explain the binding kinetics and also to relate the association and dissociation coefficients by equilibrium coefficients. ${ }^{26,27}$ A nonlinear reversible chemical reaction is generally accepted to predict the two types of drug forms. ${ }^{28}$

Vo and Meere $^{29}$ considered a nonlinear reversible binding mod- 


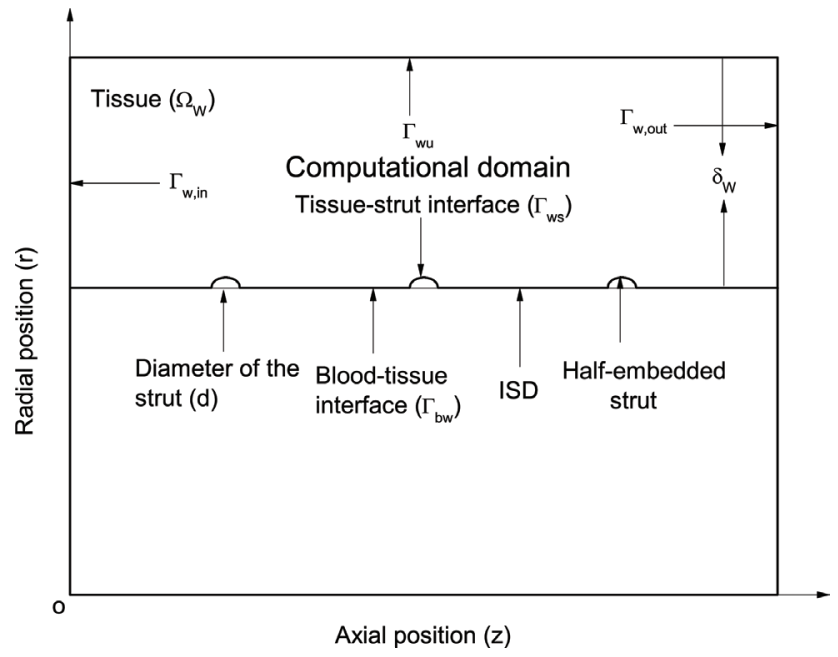

Fig. 1. Schematic diagram of the stented artery.

el to describe the release of heparin-binding growth factors from an affinity-based delivery system. Groh $e t a^{30}$ adopted a nonlinear reaction model to describe the binding of drug to binding sites within cells and also investigated the chemotherapeutic interaction with the microenvironment of cells in tumour drug delivery. A nonlinear saturable binding model was developed to describe the drug binding in arterial tissue sites, which included two phases of drug: the free drug and the bound drug. ${ }^{18,31}$

Different binding models namely, nonlinear saturable reversible binding, nonlinear saturable irreversible binding, linear reversible binding and linear irreversible binding, are demonstrated by McGinty and Pontrelli. ${ }^{32}$ However, it is well established that when the drug binds to the specific receptor (SR), there is also occurrence of non-specific binding caused by the trapping of drug in the extracellular matrix (ECM). Tzafriri et $a l^{33}$ investigated two types of binding-specific binding and non-specific binding-and both of the binding kinetics are modelled by using a nonlinear reversible chemical reaction process. Very recently, McGinty and Pontrelli ${ }^{34}$ investigated the importance of modelling the specific and nonspecific saturable binding in the arterial wall as separate phases.

Very little of this type of work has been carried out considering the specific and non-specific binding of drug, ${ }^{33,34}$ and some significant aspects remain unanswered. Tzafriri et $a^{33}$ considered only the transmural transport of eluted drug with constant release kinetics, whereas, McGinty and Pontrelli ${ }^{34}$ opined that when the ratios of SR to ECM binding site density and of SR to ECM unbinding rate are both small, drugs such as sirolimus and paclitaxel have same modes of action.

Usually, modelling with well-apposed DES represents very early stage after the implantation. The scientific interest for embedment of strut came from the need for accurate and quantitative evaluation of the vessel wall and stent interaction. The degree of stent embedment could be one of the surrogate parameters of the vessel wall-stent interaction. ${ }^{35}$ In terms of shear stress, the deeper the struts are embedded, the less disturbed the shear stress will be. ${ }^{36}$ Moreover, deeper penetration into the vessel wall increases direct contact and drug delivery, and reduces recirculation zones, which, in turn, decreases the area of the endothelisation exposed to disturbed flow, thus increasing the probability of endothelisation of adjacent tissues; ultimately, an antiproliferative and anticoagulant flow environment is established, which is the optimal condition for clinical success. ${ }^{35}$
There seems to be a down side, however, in the sense that embedded struts denote penetration of the cutting edge of the struts through vessel wall, implying larger injury of the vessel that can trigger neointimal hyperplasia. ${ }^{37}$ Even if the embedment of struts is small, a larger width of strut could contribute to larger amount of vessel wall-stent interaction. Hence, relationship between this injury (i.e. the degree of embedment and neointimal hyperplasia) will be the topic of further study. ${ }^{38}$ On that theoretical basis, we should not expect an excess of neointima, despite the embedment and injury to the vessel wall.

Keeping all the relevances in mind, the present investigation describes three-phase drug transport phenomena within the arterial wall, namely free drug, specific binding of drug with the SR and non-specific binding of drug in the ECM site from a half-embedded DES. The transport of free drug has been modelled by reactiondiffusion process, whereas the bound drug has been modelled by nonlinear reversible saturable chemical reaction. The arterial wall has been considered as a single homogeneous layer with identical diffusivity property. In this study, the therapeutic domain of length $L$ consists of three struts with centre to centre distance of $0.7 \mathrm{~mm}$ (Fig. 1). ${ }^{39,40}$ At the strut surfaces, a time-dependent drug release kinetic in exponential manner has been accounted for McGinty et al. ${ }^{41}$ The governing equations together with their physiological realistic boundary conditions are solved numerically in an explicit manner.

\section{Governing equations and boundary conditions}

A three-phase model of drug transport has been modelled in the tissue, namely free drug, ${ }^{16}$ specific binding (SR) and non-specific binding (ECM). ${ }^{42,43}$ The transport of free drug has been modelled by reaction-diffusion process and binding of drug by nonlinear saturable reversible chemical reaction. Now the dimensionless governing equations for the model considered may be written as

$$
\begin{aligned}
& \frac{\partial c_{f}}{\partial t}=\frac{1}{\varepsilon^{2}}\left(\frac{\partial^{2} c_{f}}{\partial r^{2}}+\frac{1}{r} \frac{\partial c_{f}}{\partial r}+\varepsilon^{2} \frac{\partial^{2} c_{f}}{\partial z^{2}}\right)-\frac{\partial c_{S R}}{\partial t}-\frac{\partial c_{E C M}}{\partial t}, \\
& \frac{\partial c_{S R}}{\partial t}=D a_{S R}\left\{c_{f}\left(c_{S R}^{\max }-c_{S R}\right)-\frac{c_{S R}}{k_{e q_{S R}}}\right\}, \\
& \frac{\partial c_{E C M}}{\partial t}=D a_{E C M}\left\{c_{f}\left(c_{E C M}^{\max }-c_{E C M}\right)-\frac{c_{E C M}}{k_{e q_{E C M}}}\right\},
\end{aligned}
$$

where $c_{f}, c_{S R}$ and $c_{E C M}$, normalised by initial strut drug concentration $\left(c_{0}\right)$, are the normalised concentration of free drug, specific and non-specific binding drug respectively. $r$ is the dimensionless radial coordinate and $\mathrm{z}$ is the dimensionless axial coordinate, normalised by the thickness of the arterial wall $\left(\delta_{\mathrm{W}}\right)$ and diameter of the strut $(d)$ respectively. Here, $c_{i}^{\max }$ is the dimensionless local density of binding site, normalised by initial strut drug concentration $\left(c_{0}\right) . D a_{i}\left(\frac{k_{f} c_{0} d^{2}}{D_{i}}\right)$ and $k_{c y}\left(\frac{c_{0} k_{i}}{k_{n i}}\right)$ are the Damköhler number and equilibrium constant respectively, in which $k_{f_{i}}$ and $k_{r_{i}}$ are the association and dissociation reaction rate respectively. Here and in the sequel, $\mathrm{i}=\mathrm{SR}, \mathrm{ECM}$. Here $t\left(\frac{\bar{t} D_{t}}{d^{2}}\right)$, is the dimensionless time and $\varepsilon=\left(\frac{\delta_{W}}{d}\right)$.

In the tissue, symmetry boundary conditions are applied on the proximal $\left(\Gamma_{w, i n}\right)$ and the distal $\left(\Gamma_{w, \text { out }}\right)$ walls:

$$
\frac{\partial c_{f}}{\partial z}=0 \text { on } \Gamma_{w, i n} \text { and } \Gamma_{w, o u t}
$$

At the perivascular wall, a perfect sink condition for free drug is applied:

$$
c_{f}=0 \text { at } \Gamma_{w u}
$$


A time-dependent drug release kinetic has been used at the strut surfaces: ${ }^{41}$

$$
c_{f}=e^{-\varphi t} \text { on } \Gamma_{w s} \text {, }
$$

where $\varphi=\frac{\lambda d^{2}}{D_{l}}, \lambda$ is the rate of drug release from strut surfaces.

At the blood-tissue interface $\left(\Gamma_{\mathrm{bw}}\right)$, it is assumed that the transported drug is insensitive to luminal flow, which is modelled as zero-flux condition given by

$$
\frac{\partial c_{f}}{\partial r}=0 \text { on } \Gamma_{b w}
$$

\section{Radial coordinate transformation}

In order to avoid interpolation error, we transform the therapeutic domain (Fig. 1) into a rectangular one, by making use of the following radial coordinate transformation:

$$
\xi=1+\frac{r-R_{t l}}{\Gamma_{w u}-R_{t l}} \text { where } R_{t l}=\Gamma_{b w} \cup \Gamma_{w s .}
$$

Considering this transformation, the irregular domain transforms into $[0, L] \times[1,2]$. Now using the transformation (8) the equations (1)-(7) are transformed as follows:

$$
\begin{aligned}
& \begin{aligned}
\frac{\partial c_{f}}{\partial t}= & \frac{1}{\varepsilon^{2}}\left[\frac{\partial^{2} c_{f}}{\partial \xi^{2}}\left\{\frac{1}{R^{2}}+\varepsilon^{2}\left(\frac{\partial \xi}{\partial z}\right)^{2}\right\}\right. \\
& \left.+\frac{\partial c_{f}}{\partial \xi}\left\{\frac{1}{R\left\{R(\xi-1)+R_{l l}\right\}}+\varepsilon^{2} \frac{\partial^{2} \xi}{\partial z^{2}}+\frac{\varepsilon^{2}}{R^{2}} \frac{d R}{d z}\left((\xi-1) \frac{d R}{d z}+\frac{d R_{l l}}{d z}\right)\right\}\right] \\
& +\frac{\partial^{2} c_{f}}{\partial z^{2}}+2 \frac{\partial \xi}{\partial z} \frac{\partial^{2} c_{f}}{\partial \xi \partial z}-\frac{\partial c_{S R}}{\partial t}-\frac{\partial c_{S R}}{\partial t}
\end{aligned} \\
& \frac{\partial c_{S R}}{\partial t}=D a_{S R}\left\{c_{f}\left(c_{S R}^{\max }-c_{S R}\right)-\frac{c_{S R}}{k_{e q_{S R}}}\right\} \\
& \frac{\partial c_{E C M}}{\partial t}=D a_{E C M}\left\{c_{f}\left(c_{E C M}^{\max }-c_{E C M}\right)-\frac{c_{E C M}}{k_{e q_{E C M}}}\right\} \\
& \frac{\partial c_{f}}{\partial z}=0 \text { on } z=0 \text { and } z=L \\
& c_{f}=0 \text { at } \xi=2 \\
& c_{f}=e^{-\varphi t} \text { at } \xi=1 \text { and } z \in \Gamma_{\mathrm{ws}} \\
& {\left[\frac{\partial c_{f}}{\partial \xi}\right]_{\xi=1}=0 \text { for } \mathrm{z} \in \Gamma_{b w}}
\end{aligned}
$$

\section{Method of solution}

The governing equations with the set of initial and boundary conditions are solved numerically by finite-difference scheme. Forward-time centred-space discretisation technique has been made use of in the explicit numerical scheme. Let us describe our finitedifference method in more detail: We denote $z_{i}=i \delta z, t^{\mathrm{n}}=n \delta t, \xi_{k}=k \delta \xi$, where $n$ refers to the time level, $\delta t$ the time increment and $\delta z$ is the space step size along the axial direction. Here, $\delta \xi$ denote space step sizes along the radial direction.

The finite difference approximations of (9-11) are as follows:

$$
\begin{aligned}
& \frac{c_{f, k}^{n+1}-c_{f, k}^{n}}{\delta t}=\frac{1}{\varepsilon^{2}}\left[\operatorname{diff}_{f}\right]_{i, k}^{n}-\frac{c_{S R_{i, k}}^{n+1}-c_{S R_{i, k}}^{n}}{\delta t}-\frac{c_{E C M_{i, k}}^{n+1}-c_{E C M_{i, k}}^{n},}{\delta t}, \\
& \frac{c_{S R_{i, k}}^{n+1}-c_{S R_{i, k}}^{n}}{\delta t}=\left[\operatorname{reac}_{S R}\right]_{i, k}^{n}, \\
& \frac{c_{E C M_{i, k}}^{n+1}-c_{E C M_{i, k}}^{n}}{\delta t}=\left[\operatorname{reac}_{E C M}\right]_{i, k}^{n},
\end{aligned}
$$

where the expressions for $\left[\operatorname{diff}_{f}\right]_{i, k}^{n},\left[\operatorname{reac}_{S R}\right]_{i, k}^{n},\left[\operatorname{reac}_{E C M}\right]_{i, k}^{n}$ are included in the Supplementary Term S1.

Now, the discretised equations are solved numerically in an explicit manner. No standard package has been used in the present simulation, rather the computational code has been successfully programmed using FORTRAN language.

\section{Results and discussion}

For the purpose of numerical computation of the quantities of significance, the computational domain has been confined to a finite nondimensional length of 25 and solutions are computed with the grid size of $501 \times 61$ by making use of the input values presented in Table 1. 11,16,31,33,34,39-41,44-46 The simulation concerning grid-independent study was performed for examining the error associated with the grid sizes used and displaced in Figure 2. The transmural variations of normalised bound drug concentration in SR phase at an axial distance of $z=11$ for three distinct grid sizes almost overlap on one another, which clearly establishes the correctness of the grid sizes used.

Transmural variations of free $\left(N D C_{F R E E}\right)$, bound in ECM phase $\left(N D C_{E C M}\right)$ and bound in SR phase $\left(N D C_{S R}\right)$ at three distinct nondimensional times have been depicted in Figure 3, panels a-c, respectively. Drug enters the arterial wall at $\xi=1$ in the free phase, and is rapidly bound to both ECM and SR sites. It is worthy to note that the penetration length of both free and ECM-bound drug increases with increasing time, with saturation of binding sites ultimately taking place. Moreover, the SR-bound drug is absorbed at the adventitial boundary $(\xi=2)$ with the increase of time. The free drug $\left(N D C_{F R E E}\right)$ and ECM-bound drug $\left(N D C_{E C M}\right)$ penetrate half of the thickness of the tissue at $t=0.5$, and although the $N D C_{F R E E}$ and $N D C_{E C M}$ profiles are similar, drug concentrations within ECM-bound phase are an order of magnitude greater than for the SR-bound phase. Saturation of SR-bound drug takes place with increasing time (Fig. 3c). All the above observations are in conformity with Tzafriri et $a^{33}$ McGinty and Pontrelli, ${ }^{34}$ although the embedment of stent has been ignored in the latter study.

Temporal variations of normalised mean drug concentrations are presented in Figure 4. Evidently, the concentrations of free and ECM-bound drug rise from zero to a maximum value and then slowly decay with time; however, the concentration of SRbound drug steadily increases with time considered. It is worthy to note that the peak of $N D C_{S R}$ occurs later than that of $N D C_{F R E E}$ and also more drug is contained within the ECM-bound phase than the other two phases, which are in good agreement with those of Tzafriri et $a l^{33}$ and McGinty and Pontrelli. ${ }^{34}$ By choosing $k_{f_{s}}$ $=0=k_{r_{S R}}$, we convert the model considered into the single bound phase model. Here, too, we see that the mean concentration of free drug in case of the single bound phase model is all time higher than that of the double bound phase model, which is due to less conversion of free drug into bound form in the single bound phase model (Fig. 5).

The influence of Damköhler number on the normalised concentrations of free drug, ECM-bound and SR-bound drug in the arterial tissue over a stipulated period of time is displayed in Figure $6 \mathrm{a}-\mathrm{c}$ respectively. Evidently, the mean concentration of free drug decays rapidly and also the mean concentrations of ECMand SR-bound drug attain their respective steady state for smaller Damköhler number. Spatial distribution of free, ECM-bound and SR-bound drug concentration can be visualised through Figure $7 \mathrm{a}-\mathrm{c}$ respectively. These figures clearly establish the impact of time-dependent release kinetics on the transport and retention of 
Table 1. Plausible values of involved parameters (dimensional)

\begin{tabular}{|c|c|c|c|}
\hline Description & Parameter & Value & Reference \\
\hline Diameter of the strut $(\mathrm{cm})$ & $d$ & 0.02 & {$[31,44]$} \\
\hline Interstrut distance $(\mathrm{cm})$ & $z_{\mathrm{d}}$ & 0.06 & [39] \\
\hline Wall thickness $(\mathrm{cm})$ & $\delta_{\mathrm{w}}$ & 0.1 & {$[16,45]$} \\
\hline Free drug diffusion coefficient $\left(\mathrm{cm}^{2} \cdot \mathrm{s}^{-1}\right)$ & $D_{\mathrm{t}}$ & $10^{-9}$ & {$[40,46]$} \\
\hline Initial strut drug concentration $\left(\mathrm{mol} \cdot \mathrm{cm}^{-3}\right)$ & $c_{0}$ & $10^{-6}$ & {$[11]$} \\
\hline Association rate constant in ECM-bound phase $\left(\left(\mathrm{mol} \cdot \mathrm{cm}^{-3} \cdot \mathrm{s}\right)^{-1}\right)$ & $k_{f_{E C M}}$ & $2 \times 10^{6}$ & {$[33,34]$} \\
\hline Dissociation rate constant in ECM-bound phase $\left(\mathrm{s}^{-1}\right)$ & $k_{r_{E C M}}$ & $5.22 \times 10^{-6}$ & {$[33,34]$} \\
\hline Local density in ECM binding site $\left(\mathrm{mol} \cdot \mathrm{cm}^{-3}\right)$ & $\overline{\boldsymbol{C}}_{E C M}^{\max }$ & $3.63 \times 10^{-7}$ & {$[33,34]$} \\
\hline Association rate constant in SR-bound phase $\left(\left(\mathrm{mol} \cdot \mathrm{cm}^{-3} \cdot \mathrm{s}^{-1}\right)^{-1}\right)$ & $k_{f_{S R}}$ & $8 \times 10^{8}$ & {$[33,34]$} \\
\hline Dissociation rate constant in SR-bound phase $\left(\mathrm{s}^{-1}\right)$ & $k_{r_{S R}}$ & $1.6 \times 10^{-4}$ & {$[33,34]$} \\
\hline Local density in SR binding site $\left(\mathrm{mol} \cdot \mathrm{cm}^{-3}\right)$ & $\bar{C}_{S R}^{\max }$ & $3.3 \times 10^{-9}$ & {$[33,34]$} \\
\hline Drug release rate $\left(\mathrm{s}^{-1}\right)$ & $\lambda$ & $10^{-5}$ & [41] \\
\hline
\end{tabular}

drug in stent-based delivery.

\section{Conclusion and study limitation}

In this numerical study, we proposed two-dimensional axi-symmetric models of drug transport eluted from a DES. Following Tzafriri et $a l^{33}$ and McGinty and Pontrelli, ${ }^{34}$ we considered a three-phase model, capable of predicting the time-dependent delivery of free drug and its ECM- and SR-binding in arterial tissue with the binding site actions modelled using a nonlinear re- versible saturable chemical reaction. The transport of free drug was modelled as an unsteady reaction-diffusion process, while both the bound drugs were modelled as a reaction process only. The simulated results predict the saturation of binding sites that takes place with increasing time and SR-bound drug is totally absorbed at the adventitial boundary. This study also highlights the fact that the concentration of free drug is always higher when the model reduces to two-phase, in which a single bound phase is considered. Another important observation noted is that the concentration of free drug decays rapidly and the earlier saturation of binding sites take place in case of smaller Damköhler

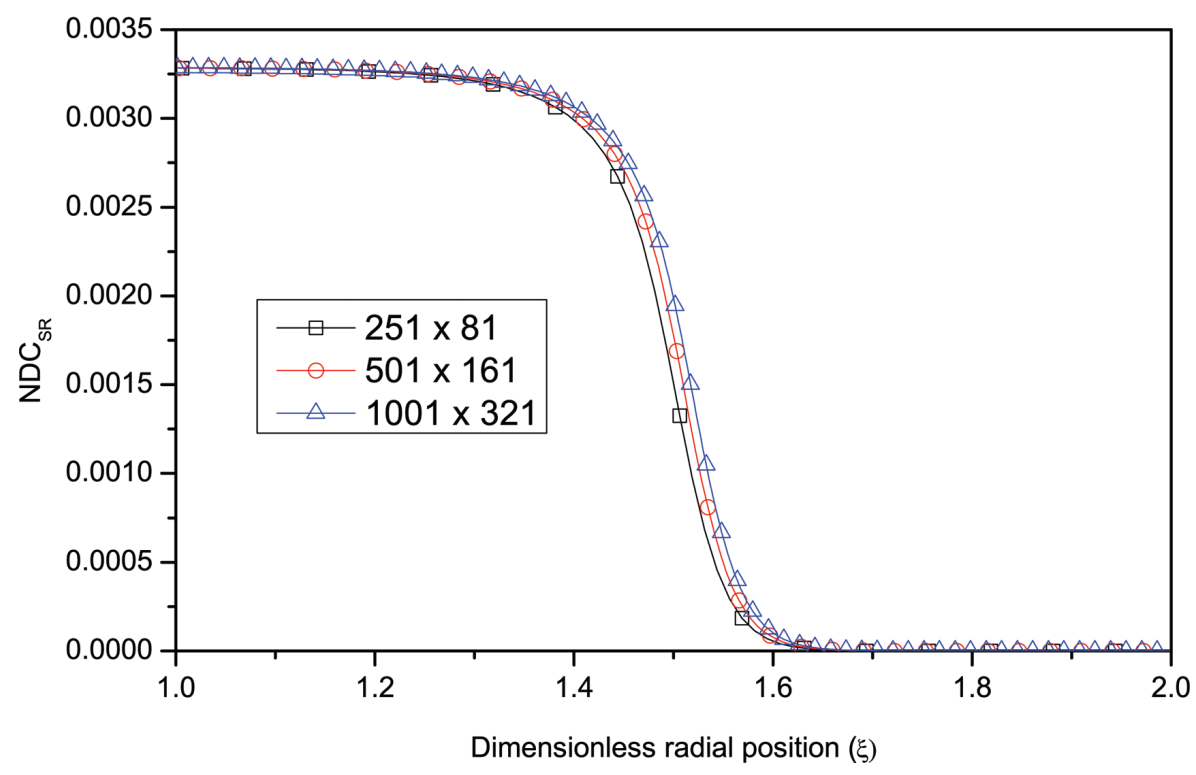

Fig. 2. Transmural variation of normalised bound drug concentration in $\mathrm{SR}$ phase $\left(N D C_{S R}\right)$ with different grid sizes at $\mathrm{z}=11\left(D a_{E C M}=8.0 \times 10^{5}, \mathrm{Da} \mathrm{SR}_{\mathrm{S}}=32.0 \times 10^{7}\right.$, $\left.\mathrm{k}_{\mathrm{eq}}=3.8 \times 10^{2}, \mathrm{k}_{\mathrm{eq}_{\mathrm{SR}}}=5.0 \times 10^{6}\right)$. 
A

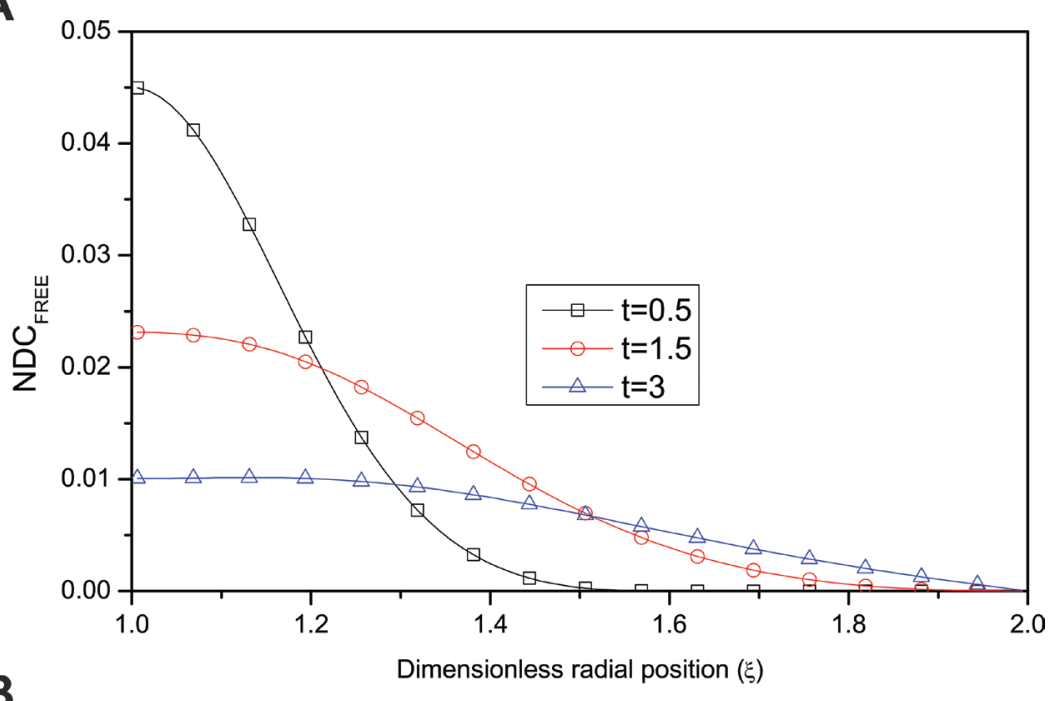

B

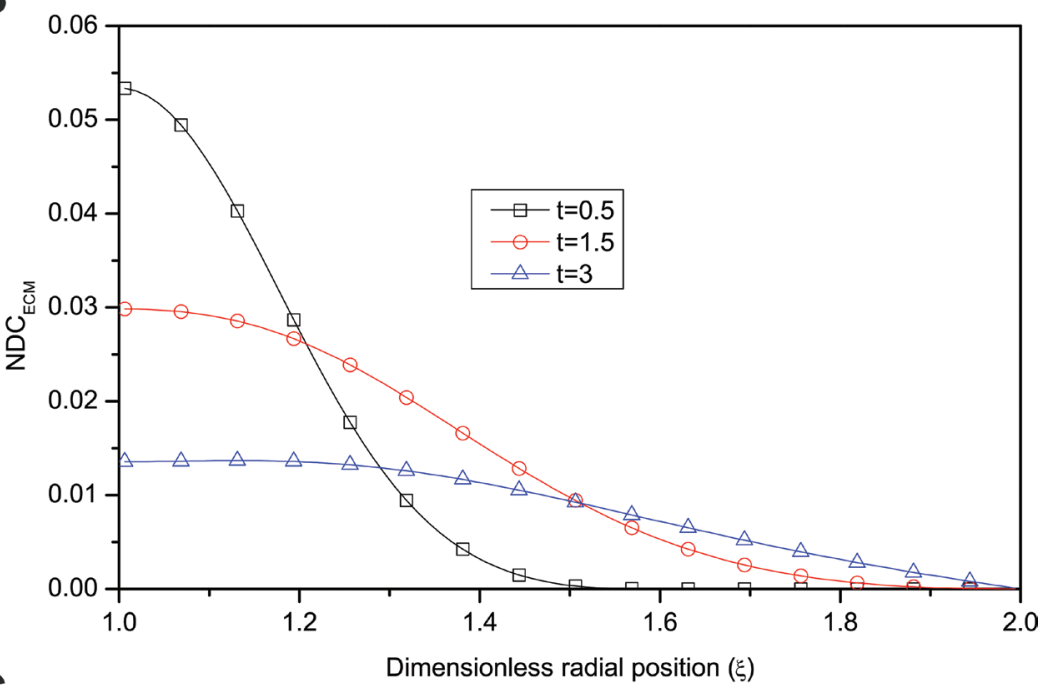

C

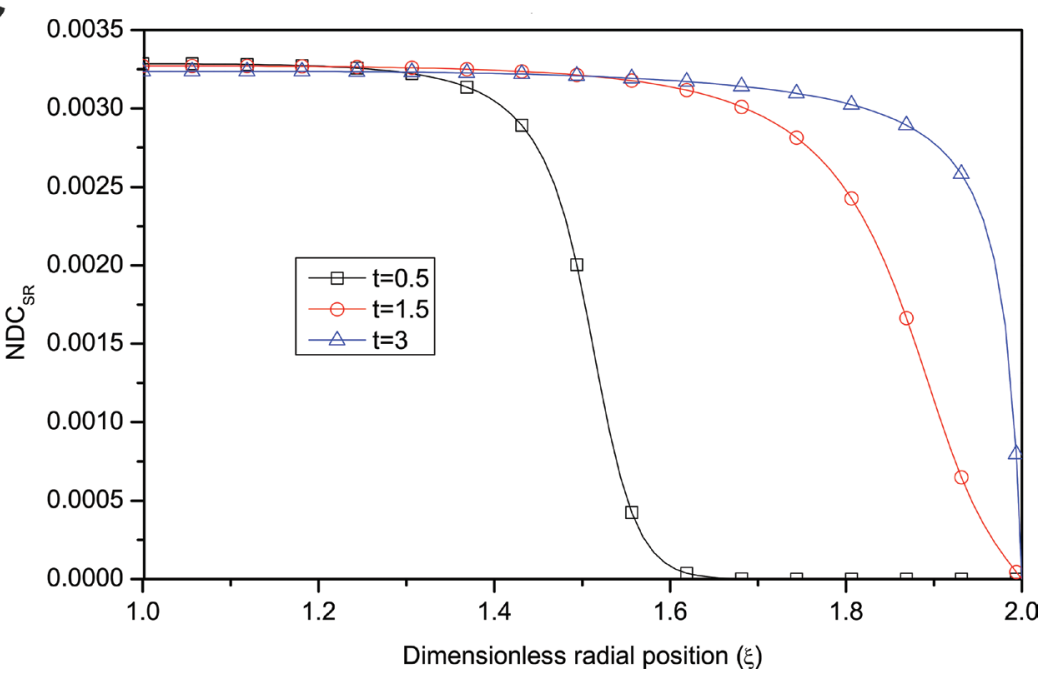

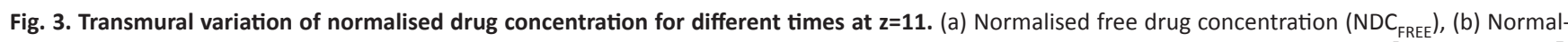
ised bound drug concentration in ECM phase $\left(\mathrm{NDC}_{\mathrm{ECM}}\right)$, (c) Normalised bound drug concentration in $\mathrm{SR}$ phase $\left(\mathrm{NDC}_{\mathrm{SR}}\right)\left(D a_{E C M}=8.0 \times 10^{5}, \mathrm{Da} \mathrm{a}_{\mathrm{SR}}=32.0 \times 10^{7}\right.$, $\left.\mathrm{k}_{\mathrm{eq}_{\mathrm{ECM}}}=3.8 \times 10^{2}, \mathrm{k}_{\mathrm{eq}_{\mathrm{SR}}}=5.0 \times 10^{6}\right)$. 


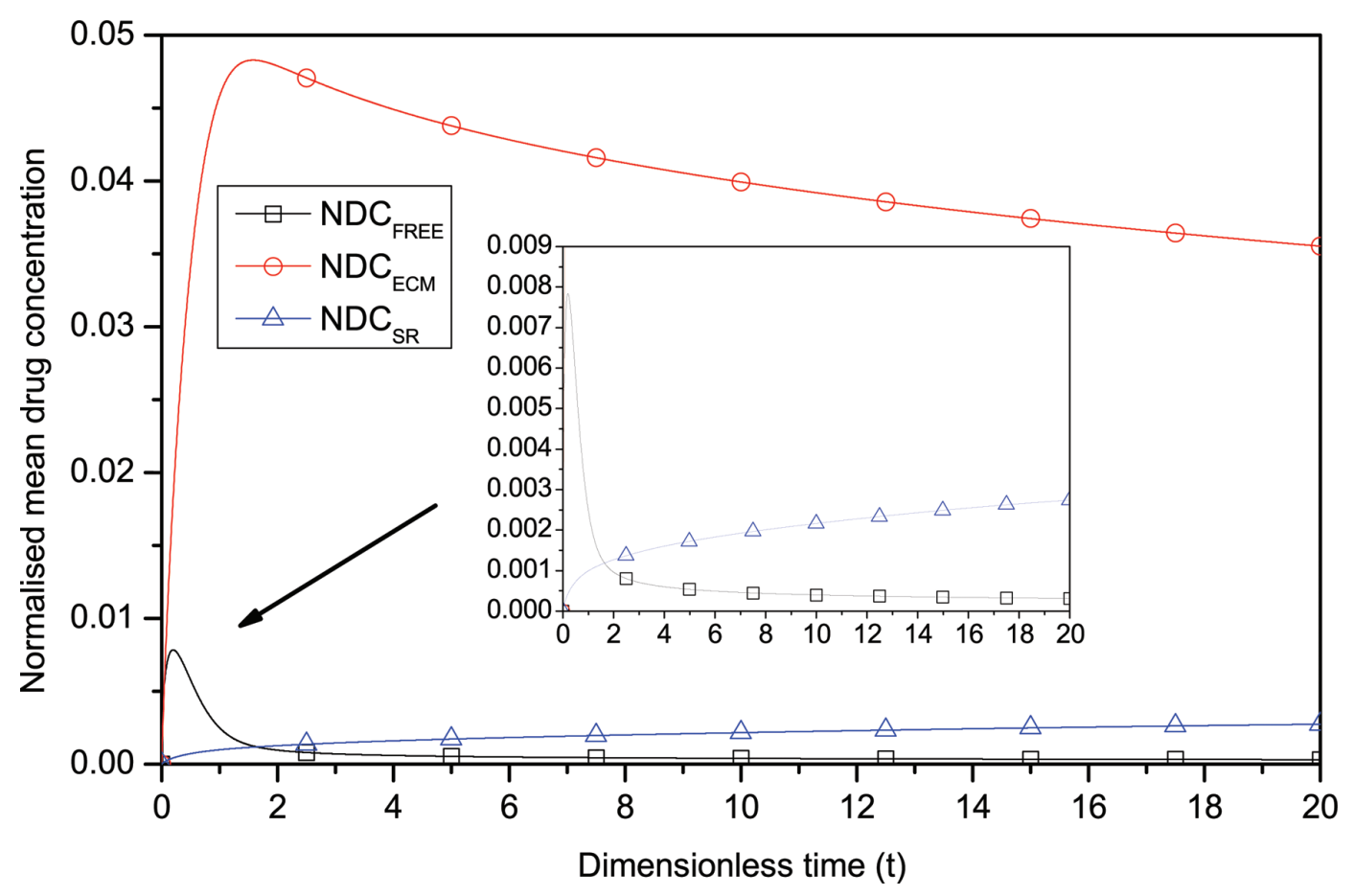

Fig. 4. Temporal variation of normalised mean drug concentration $\left(\mathrm{D} a_{E C M}=8.0 \times 10^{5}, \mathrm{Da}_{\mathrm{SR}}=32.0 \times 10^{7}, \mathrm{k}_{\mathrm{eq}_{\mathrm{ECM}}}=3.8 \times 10^{2}, \mathrm{k}_{\mathrm{eq}_{\mathrm{SR}}}=5.0 \times 10^{6}\right)$.

number.

As with the case of any computational model study, our study was based on a number of assumptions made regarding selected parameters (Table 1) and the boundary conditions that were as- signed due to non-availability of data in the literature. Although not ideal, derivation of all these parameters from human tissues may not be feasible and hence our assumption may be considered as an approximation towards quantifying arterial pharmacokinet-

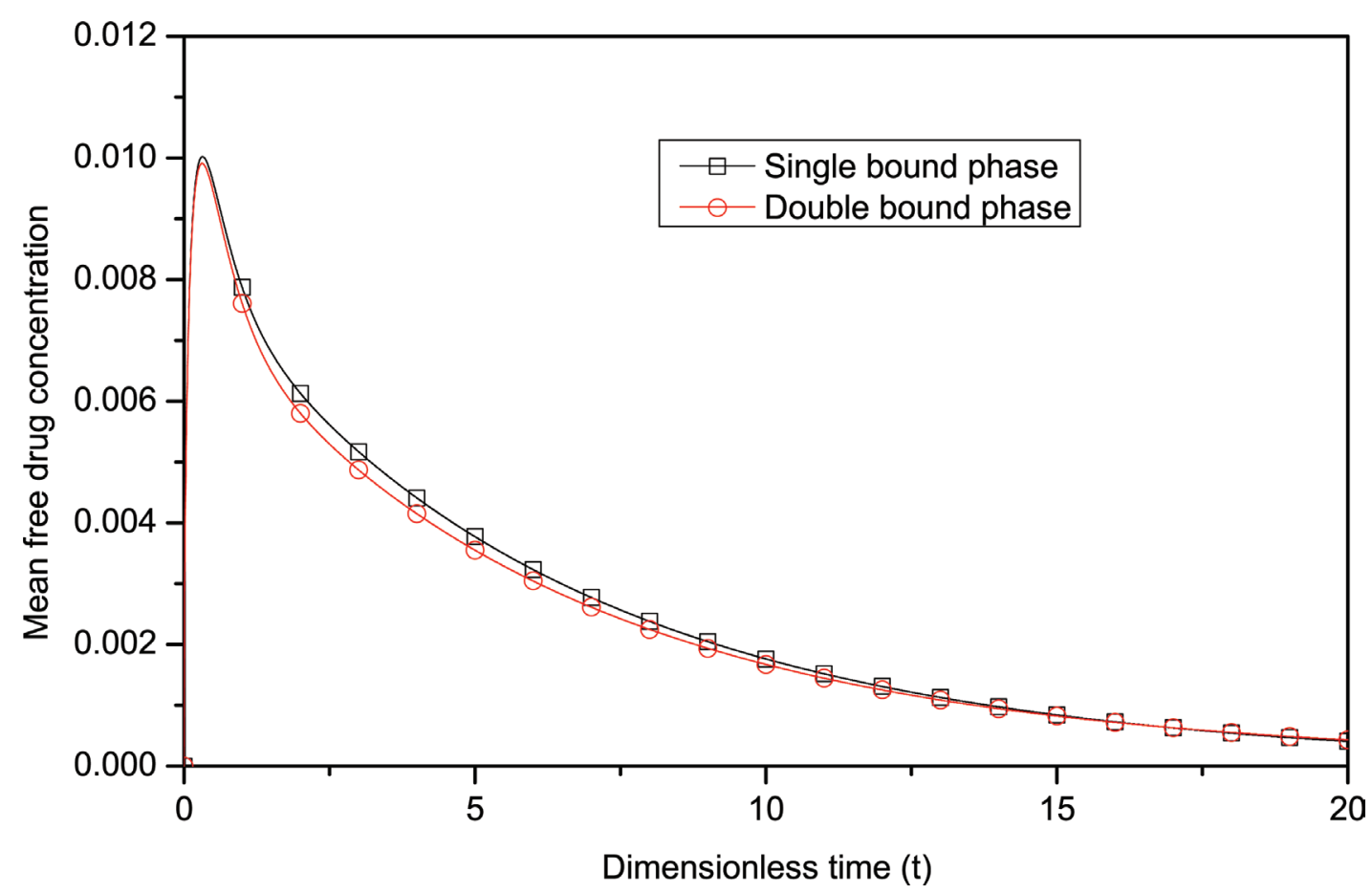

Fig. 5. Temporal variation of normalised mean free drug concentration for different binding phase $\left(D a_{E C M}=8.0 \times 10^{5}, D a_{S R}=32.0 \times 10^{7}, k_{\text {eq }}=3.8 \times 10^{2}\right.$, $\left.\mathrm{k}_{\text {eqs }}=5.0 \times 10^{6}\right)$. 


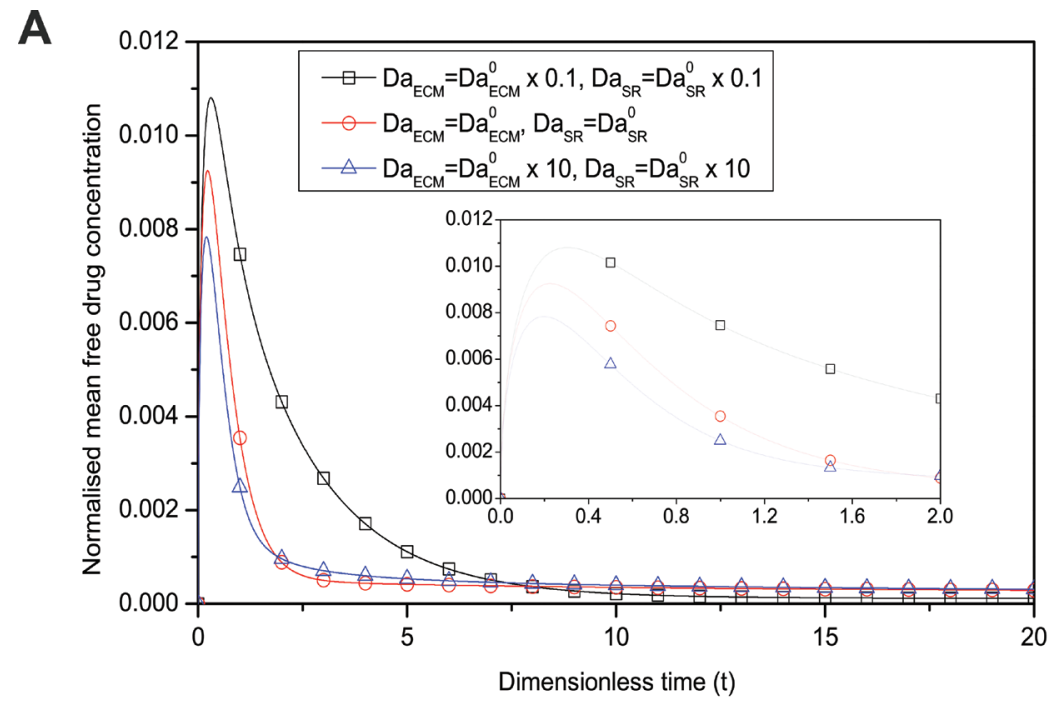

B

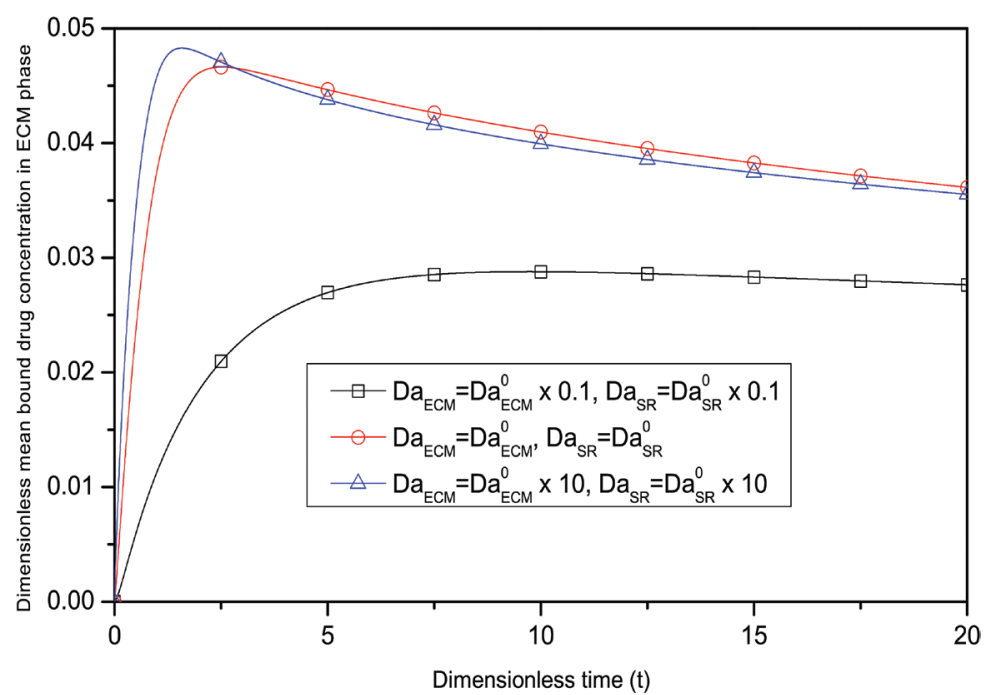

C

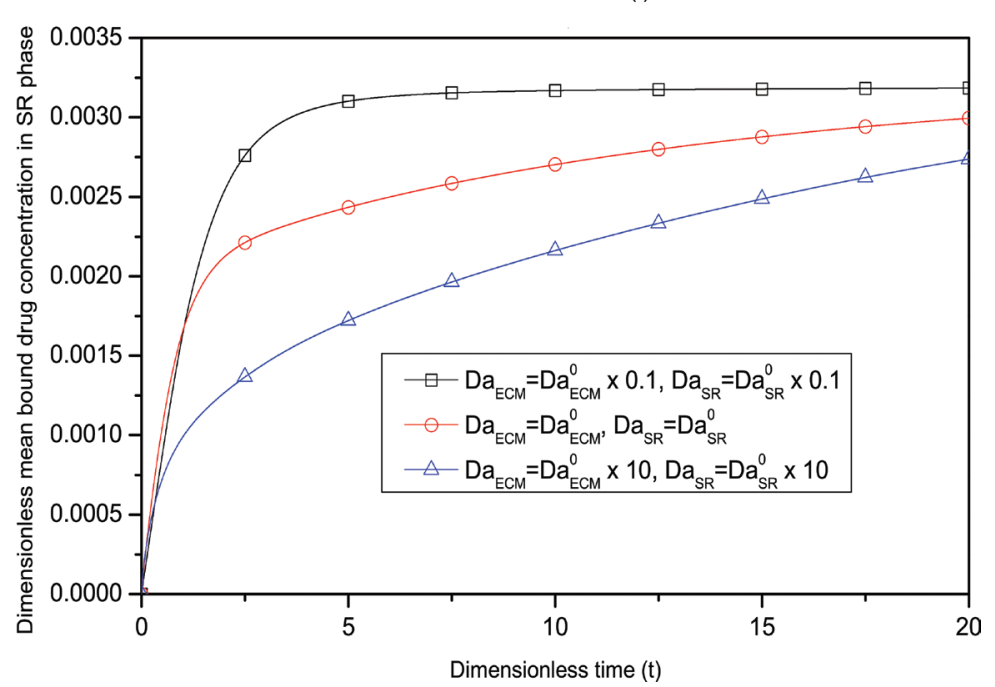

Fig. 6. Temporal variation of normalised mean drug concentration for different Damköhler numbers. (a) Normalised free drug concentration, (b) Normalised bound drug concentration in ECM phase, (c) Normalised bound drug concentration in SR phase $\left(D a_{E C M}=8.0 \times 10^{5}, D_{S R}=32.0 \times 10^{7}, k_{\text {eq }}=3.8 \times 10^{2}\right.$, $\left.\mathrm{k}_{\mathrm{eq}_{\mathrm{sR}}}=5.0 \times 10^{6}\right)$. 
A

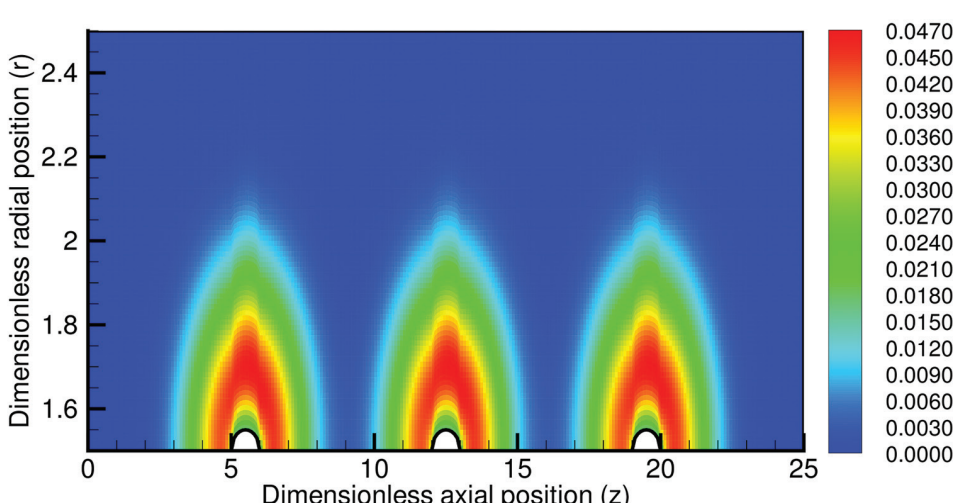

B

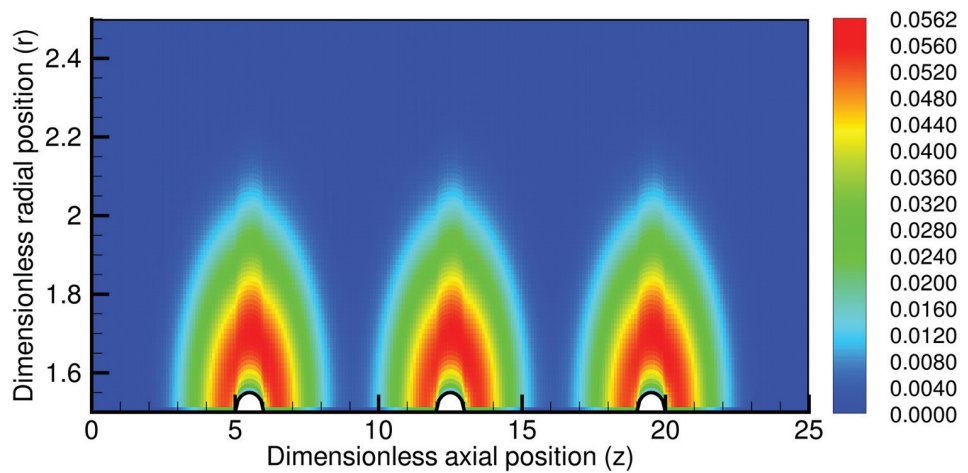

C

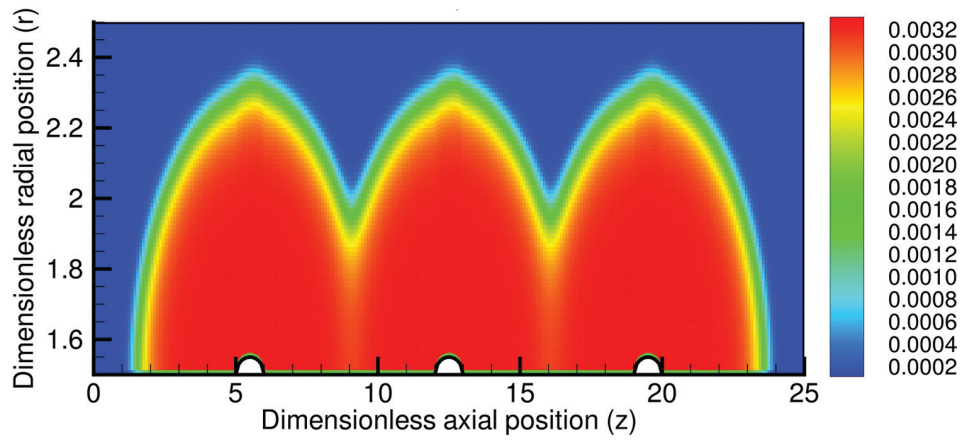

Fig. 7. Visual representation of normalised drug concentration. (a) free drug concentration, (b) bound drug concentration in ECM phase, (c) bound drug concentration in SR phase $\left(D a_{E C M}=8.0 \times 10^{5}, \mathrm{Da}_{\mathrm{SR}}=32.0 \times 10^{7}, \mathrm{k}_{\mathrm{eq}_{\mathrm{ECM}}}=3.8 \times 10^{2}, \mathrm{k}_{\mathrm{eq}_{\mathrm{SR}}}=5.0 \times 10^{6}\right)$.

ics in stent-based delivery.

\section{Future direction}

With the rapid ascent of stent-based drug delivery in the treatment of vascular disease, many important issues concerning drug delivery and its retention in the arterial tissue need to be addressed. For realistic modelling, the inclusion of luminal flow along with its pulsatility would certainly predict the delivery system one step closer to the real situation. Future directions may also include heterogeneous tissue composition comprising of healthy tissue and regions of fibrous, fibro-fatty, calcified and necrotic core lesions, with varying diffusivities. The effect of porosity and tortuosity of the arterial tissue may not be ruled out for further research.

It is well-established that the presence of stent coating together with its design greatly influence the distribution and retention of drug within the vessel wall but, ${ }^{33,34}$ for simplicity, the stent-coating system is not taken into account in the present study, which is in agreement with the numerical evidence proposed in. ${ }^{8,26,45}$ Following McGinty et $a l,{ }^{47} \mathrm{Zhu}$ and Braatz, ${ }^{48}$ the effects of variable porosity, percolation and biodegradability of the stent coating may be distinct topics of future research, and which we intend to include in our further studies.

\section{Acknowledgments}

The authors are grateful to the learned reviewers for careful consideration of the manuscript and for valuable suggestions. Partial financial support for carrying out this investigation was provided by the Special Assistance Programme (SAP-III) sponsored by the University Grants Commission, New Delhi, India (Grant No. F.510/3/DRS-III/2015 (SAP-III)). 


\section{Conflict of interest}

The authors have no conflict of interests related to this publication.

\section{Author contributions}

Designing and performing the research as well as writing the paper (APM and PKM).

\section{Supporting information}

Supplementary material for this article is available at https://doi.org/ 10.14218/JERP.2017.00001.

Data S1. Supplementary Data.

\section{References}

[1] Hill RA, Dündar Y, Bakhai A, Dickson R, Walley T. Drug-eluting stents: an early systematic review to inform policy. Eur Heart J 2004;25(11):902-919. doi:10.1016/j.ehj.2004.03.023.

[2] Hossainy S, Prabhu S. A mathematical model for predicting drug release from a biodurable drug-eluting stent coating. J Biomed Mater Res A 2008;87(2):487-493. doi:10.1002/jbm.a.31787.

[3] Pontrelli G, de Monte F. Mass diffusion through two-layer porous media: an application to the drug-eluting stent. Int J Heat Mass Transf 2007;50(17):3658-3669. doi:10.1016/j.ijheatmasstransfer.2006.11.003.

[4] Pontrelli G, de Monte F. A two-phase two-layer model for transdermal drug delivery and percutaneous absorption. Math Biosci 2014;257:96-103. doi:10.1016/j.mbs.2014.05.001.

[5] Delfour MC, Garon A, Longo V. Modeling and design of coated stents to optimize the effect of the dose. SIAM J Appl Math 2005;65(3):858881. doi:10.1137/S0036139902411600.

[6] Grassi M, Pontrelli G, Teresi L, Grassi G, Comel L, Ferluga A, et al. Novel design of drug delivery in stented arteries: a numerical comparative study. Math Biosci Eng 2009;6(3):493-508. doi:10.3934/ mbe.2009.6.493.

[7] Hwang CW, Wu D, Edelman ER. Physiological transport forces govern drug distri bution for stent-based delivery. Circulation 2001;104(5):600-605. doi:10.1161/hc3101.092214.

[8] Mandal AP, Sarifuddin, Mandal PK. An unsteady analysis of arterial drug transport from half-embedded drug-eluting stent. Appl Math Comput 2015;266:968-981. doi:10.1016/j.amc.2015.06.033.

[9] Saha R, Misra JC, Sarifuddin, Mandal PK. Impact of luminal flow on mass transport through coronary arteries: a study relevant to drugeluting stent. Int J Math Comput 2016;27(3):40-58.

[10] Zunino P. Multidimensional pharmacokinetic models applied to the design of drug-eluting stents. Cardiovasc Eng Int J 2004;4(2):181191. doi:10.1023/B:CARE.0000031547.39178.cb.

[11] O'Brien CC, Kolachalama VB, Barber TJ, Simmons A, Edelman ER. Impact of flow pulsatility on arterial drug distribution in stent-based therapy. J Control Release 2013;168(2):115-124. doi:10.1016/j.jconrel.2013.03.014

[12] Cutri E, Zunino P, Morlacchi S, Chiastra C, Migliavacca F. Drug delivery patterns for different stenting techniques in coronary bifurcations: a comparative computational study. Biomech Model Mechanobiol 2013;12(4):657-669. doi:10.1007/s10237-012-0432-5.

[13] Hose DR, Narracott AJ, Griffiths B, Mahmood S, Gunn J, Sweeney D. A thermal analogy for modelling drug elution from cardiovascular stents. Comput Methods Biomech Biomed Engin 2004;7(5):257-264. doi:10.1080/10255840412331303140.

[14] Creel CJ, Lovich MA, Edelman ER. Arterial paclitaxel distribution and deposition. Circ Res 2000;86(8):879-884. doi:10.1161/01.
RES.86.8.879

15] Ravikumar P, Bharathiraja E, Tharani V, Yamuna R, Yamunarani T. Design and analysis of coronary stent. International Journal of Healthcare Technology and Management 2011;12(5-6):447-456. doi:10.1504/IJHTM.2011.042374.

[16] Balakrishnan B, Dooley J, Kopia G, Edelman ER. Thrombus causes fl2uctuations in arterial drug delivery from intravascular stents. J Control Release 2008;131(3):173-180. doi:10.1016/j.jconrel.2008. 07.027 .

[17] Kolachalama VB, Levine AD, Edelman ER. Luminal flow amplifies stent-based drug deposition in arterial bifurcations. PLoS One 2009;4(12):e8105. doi:10.1371/journal.pone.0008105.

[18] Bozsak F, Gonzalez-Rodriguez D, Sternberger Z, Belitz P, Bewley $\mathrm{T}$, Chomaz JM, et al. Optimization of drug delivery by drug-eluting stents. PloS One 2015;10(6):e0130182. doi:10.1371/journal. pone. 0130182

[19] Mongrain R, Leask R, Brunette J, Faik I, Bulman-Feleming N, Nguyen T. Numerical modeling of coronary drug eluting stents. Stud Health Technol Inform 2005;113:443-458.

[20] Fattori R, Piva T. Drug-eluting stents in vascular intervention. Lancet 2003;361(9353):247-249. doi:10.1016/S0140-6736(03)12275-1.

[21] Pontrelli G, de Monte F. A multi-layer porous wall model for coronary drug-eluting stents. Int J Heat Mass Transf 2010;53(19):3629-3637. doi:10.1016/j.ijheatmasstransfer.2010.03.031.

[22] Sarifuddin, Mandal PK. Effect of diffusivity on the transport of drug eluted from drug-eluting stent. Int J Appl Comput Math 2016;2(2):291-301. doi:10.1007/s40819-015-0060-8.

[23] Lauffenburger DA, Linderman J. Receptors: models for binding, trafficking, and signaling. Oxford University Press, 1993.

[24] Saltzman WM. Drug delivery: engineering principles for drug therapy. Oxford University Press, USA, 1993.

[25] Hwang CW, Wu D, Edelman ER. Impact of transport and drug properties on the local pharmacology of drug-eluting stents. Int J Cardiovasc Intervent 2003;5(1):7-12. doi:10.1080/14628840304614.

[26] Horner M, Joshi S, Dhruva V, Sett S, Stewart S. A two-species drug delivery model is required to predict deposition from drug-eluting stents. Cardiovasc Eng Tech 2010;1(3):225-234. doi:10.1007/s13239010-0016-4.

[27] McGinty S, McKee S, Wadsworth RM, McCormick C. Modelling drugeluting stents. Math Med Biol 2011;28(1):1-29. doi:10.1093/imam$\mathrm{mb} / \mathrm{dqq} 003$.

[28] Sakharov DV, Kalachev LV, Rijken DC. Numerical simulation of local pharmacokinetics of a drug after intravascular delivery with an eluting stent. J Drug Target 2002;10(6):507-513. doi:10.1080/10611860 21000038382.

[29] Vo TT, Meere MG. Minimizing the passive release of heparin-binding growth factors from an affinity-based delivery system. Math Med Biol 2013;30(4):357-382. doi:10.1093/imammb/dqs027.

[30] Groh CM, Hubbard ME, Jones PF, Loadman PM, Periasamy N, Sleeman $\mathrm{BD}$, et al. Mathematical and computational models of drug transport in tumours. J R Soc Interface 2014;11(94):20131173. doi:10.1098/rsif.2013.1173.

[31] Bozsak F, Chomaz JM, Barakat Al. Modeling the transport of drugs eluted from stents: physical phenomena driving drug distribution in the arterial wall. Biomech Model Mechanobiol 2014;13(2):327-347. doi:10.1007/s10237-013-0546-4.

[32] McGinty S, Pontrelli G. A general model of coupled drug release and tissue absorption for drug delivery devices. J Control Release 2015;217:327-336. doi:10.1016/j.jconrel.2015.09.025.

[33] Tzafriri AR, Groothuis A, Price GS, Edelman ER. Stent elution rate determines drug deposition and receptor-mediated effects. J Control Release 2012;161(3):918-926. doi:10.1016/j.jconrel.2012.05.039.

[34] McGinty S, Pontrelli G. On the role of specific drug binding in modelling arterial eluting stents. J Math Chem 2016;54(4):967-976. doi:10.1007/s10910-016-0618-7.

[35] Jiménez JM, Davies PF. Hemodynamically driven stent strut design. Ann Biomed Eng 2009;37(8):1483-1494. doi:10.1007/s10439-0099719-9.

[36] Mejia J, Ruzzeh B, Mongrain R, Leask R, Bertrand OF. Evaluation of the effect of stent strut profile on shear stress distribution using statistical moments. Biomed Eng Online 2009;8:8. doi:10.1186/1475- 
925X-8-8.

[37] Gunn J, Arnold N, Chan K, Shepherd L, Cumberland D, Crossman D. Coronary artery stretch versus deep injury in the development of in-stent neointima. Heart 2002;88(4):401-405. doi:10.1136/ heart.88.4.401.

[38] Serruys PW, Suwannasom P, Nakatani S, Onuma Y. Snowshoe versus ice skate for scaffolding of disrupted vessel wall. JACC Cardiovasc Interv 2015;8(7):910-913. doi:10.1016/j.jcin.2015.04.005.

[39] Ferdous J, Chong CK. Effect of atherosclerotic plaque on drug delivery from drug-eluting stent. In: Lim C.T., Goh J.C.H. (eds) 13th International Conference on Biomedical Engineering. IFMBE Proceedings. Springer, Berlin, Heidelberg; 2007;23:1519-1522. doi:10.1007/9783-540-92841-6_376.

[40] Mongrain R, Faik I, Leask RL, Rodés-Cabau J, Larose E, Bertrand OF. Effects of diffusion coefficients and struts apposition using numerical simulations for drug eluting coronary stents. J Biomech Eng 2007;129(5):733-742. doi:10.1115/1.2768381.

[41] McGinty S, Wheel M, McKee S, McCormick C. Does anisotropy promote spatial uniformity of stent-delivered drug distribution in arterial tissue? Int J Heat Mass Transf 2015;90:266-279. doi:10.1016/j. ijheatmasstransfer.2015.06.061.

[42] Bierer BE, Mattila PS, Standaert RF, Herzenberg LA, Burakoff SJ, Crabtree $G$, et al. Two distinct signal transmission pathways in $T$ lymphocytes are inhibited by complexes formed between an immunophilin and either FK506 or rapamycin. Proc Natl Acad Sci U S A 1990;87(23):9231-9235.

[43] Levin $A D$, Jonas $M$, Hwang CW, Edelman ER. Local and systemic drug competition in drug-eluting stent tissue deposition properties. J Control Release 2005;109(1):236-243. doi:10.1016/j.jconrel.2005.09.041.

[44] Vairo G, Cioffi M, Cottone R, Dubini G, Migliavacca F. Drug release from coronary eluting stents: a multidomain approach. J Biomech 2010;43(8):1580-1589. doi:10.1016/j.jbiomech.2010.01.033.

[45] Balakrishnan B, Tzafriri AR, Seifert P, Groothuis A, Rogers C, Edelman ER. Strut position, blood flow, and drug deposition implications for single and overlapping drug-eluting stents. Circulation 2005;111(22):29582965. doi:10.1161/CIRCULATIONAHA.104.512475.

[46] Levin AD, Vukmirovic N, Hwang CW, Edelman ER. Specific binding to intracellular proteins determines arterial transport properties for rapamycin and paclitaxel. Proc Natl Acad Sci U S A 2004;101(25):94639467. doi:10.1073/pnas.0400918101.

[47] McGinty S, King D, Pontrelli G. Mathematical modelling of variable porosity coatings for controlled drug release. Med Eng Phys 2017; Epub 2017 Apr 29. doi:10.1016/j.medengphy.2017.04.006.

[48] Zhu X, Braatz RD. Modeling and analysis of drug-eluting stents with biodegradable plga coating: consequences on intravascular drug delivery. J Biomech Eng 2014;136(11):111004. doi:10.1115/1.4028135. 